\section{Palofra}

acceso $\partial$ abierto

Cómo citar: López, B. y Gómez, H. (2020). Imaginarios sociales sobre el territorio y los retos que desencadenan para construir paz en Colombia. Palobra, 20(2), 251-272.

10.32997/2346-2884-vol.20-num.2-2020-3318

Recibido: 9 de junio de 2020.

Aprobado: 22 de septiembre de 2020.

Autor de correspondencia:

Blanca Aracely López Rueda

aracely.lopez@upb.edu.co

Editora: Rosario Blanco Bello. Universidad de Cartagena-Colombia.

Tipología IBN Publindex:

Artículo de Investigación Científica.

Copyright: (ㅇ 2020. López, B. y Gómez, H. Este es un artículo de acceso abierto, distribuido bajo los términos de la licencia https://creativecommons.org/licenses/by-nc$\underline{\mathrm{sa} / 4.0 / \text { la cual permite el uso sin restricciones, distribución }}$ y reproducción en cualquier medio, siempre y cuando que el original, el autor y la fuente sean acreditados.

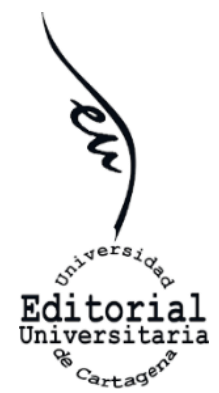

\title{
Imaginarios sociales sobre el territorio y los retos que desencadenan para construir paz en Colombia ${ }^{1}$
}

\author{
Social imaginaries about the territory and the challenges they \\ trigger to build peace in Colombia
}

Blanca Aracely López Rueda iD

Universidad Pontificia Bolivariana, Colombia, aracely.lopez@upb.edu.co

Héctor Mauricio Gómez Mora

Universidad Pontificia Bolivariana, Colombia, hector.gomez@upb.edu.co

\begin{abstract}
RESUMEN
Reconociendo que la paz en Colombia no se logra con el silenciamiento de las armas y que se necesita de múltiples iniciativas para resolver las cuestiones estructurales que desencadenan los conflictos en las comunidades y, además, que permitan reparar los impactos que esto ha causado en el tejido social, se desarrolló el proyecto, 'Pescando historias. Memorias de un llanitero', en el corregimiento El Llanito del municipio de Barrancabermeja, Colombia. Esta investigación cualitativa de tipo Investigación Acción implementó una estrategia educomunicativa para promover la pesca artesanal como forma amable de explotación de los recursos naturales en la ciénaga El Llanito, a partir de los imaginarios de adolescentes y jóvenes. En el presente artículo se dará cuenta de los imaginarios encontrados respecto a cuatro categorías: pesca artesanal, ciénaga, Lucho Arango y el territorio, y se analizarán los retos que estas concepciones suponen para fomentar procesos de construcción de paz con enfoque territorial.
\end{abstract}

Palabras clave: imaginarios; paz territorial; medio ambiente; conflicto armado.

\begin{abstract}
Recognizing that peace-building in Colombia cannot be achieved by silencing arms and that multiple initiatives are needed to resolve the structural issues that trigger conflicts in communities and, furthermore, to repair the impacts that this has caused in the social fabric, the development of the project, 'Pescando Historias' (Fishing Stories), was proposed to the current Ministry of Science and Technology. Memorias de un Llanitero', in the corregimiento El Llanito in the municipality of Barrancabermeja, Colombia. The general

\footnotetext{
${ }^{1}$ Artículo derivado del macroproyecto "Reconstruir lo que se perdió a través de un caso de memoria histórica en el Departamento de Santander" identificado con el código 035-0119-3200. Esta nueva investigación se denominó "Pescando historias. Memorias de un Llanitero" y se llevó a cabo en el corregimiento El Llanito, municipio de Barrancabermeja, fue financiada con recursos del actual Ministerio de Ciencia y Tecnología a través de la convocatoria 812 del 2018 para Jóvenes Investigadores e Innovadores por la paz y la Universidad Pontificia Bolivariana seccional Bucaramanga. Inició de manera formal el 28 de mayo y tuvo una duración de un año. El convenio especial de cooperación que se estableció para su realización se radicó con el número: 80740-300-2019
} 
objective of this qualitative research of the Action Research type was to implement an educational-communicative strategy that promotes artisanal fishing as a kind form of exploitation of natural resources in the marsh $\mathrm{El}$ Llanito, based on the imaginations of adolescents and young people. In consideration of the above, the present article will describe the imaginary of adolescents and young people in the San Marcos Educational Institution with respect to four categories: artisanal fishing, the marsh, Lucho Arango and the territory, an investigation that was supported by focus group techniques and semi-structured interviews; and will analyze the implications that these conceptions as challenges for promoting peace building processes with a territorial approach.

Keywords: imaginary; territorial peace; environment; armed conflict.

\section{INTRODUCCIÓN}

El corregimiento El Llanito está ubicado en el municipio de Barrancabermeja en la región del Magdalena Medio y se caracteriza por estar a la ribera de la ciénaga que lleva por nombre el mismo del territorio. La ciénaga tiene 1.019 Ha, un perímetro de 19.180 metros y 9.929 metros de caños, los cuales son artificiales. Teniendo en cuenta un estudio realizado por Jiménez Segura en el 2012, las principales afectaciones de la ciénaga, las cuales repercuten en la transformación de los humedales de Barrancabermeja, se relacionan con "sedimentación, ganadería, extracción de petróleo, pesca con técnicas inadecuadas, agricultura intensiva, densidad ribereña y residuos humanos" (p. 86), así mismo, sostienen que, de las 35 ciénagas estudiadas en el Magdalena, esta ocupa el puesto número ocho dentro de las más afectadas. En lo relacionado con la ganadería en un informe elaborado por el Centro Nacional de Memoria Histórica (2014), se indica que el 74\% de las tierras aledañas a este recurso hídrico son utilizadas para la ganadería con reses y búfalos.

En la década de 1990 y tras una mortandad de peces en la ciénaga, en la que se estima que murieron cerca de dos millones de peces, se conformó APALL, hoy en día la Asociación de Pescadores Artesanales y Afrodescendientes del Llanito, quienes por ese entonces y acudiendo a la ley, interpusieron una acción popular contra Ecopetrol por daños y perjuicios ocasionados al ecosistema y a la economía de los pescadores; sin embargo, después de casi veinte años las autoridades competentes no han esclarecido la responsabilidad de la petrolera en los hechos ni han adelantado acciones para reparar los daños que le causaron a la comunidad.

A lo largo de la historia del conflicto armado interno del país diferentes grupos al margen han querido apropiarse de las riquezas que hay en estas tierras y en su afán por tener el control, han perpetrado crímenes atroces. Hace aproximadamente diez años, la banda criminal denominada Los Rastrojos, un 
grupo disidente de los paramilitares desmovilizados en el gobierno de Álvaro Uribe Vélez, acabaron con la vida de Luis Alberto Arango el 12 de febrero del 2009, un hombre que desde el principio se dedicó a ser guardián de la ciénaga y el ecosistema hídrico, lo cual lo convirtió en líder ambiental y defensor de la pesca artesanal.

Aunque "fue asesinado por la agudización del conflicto entre pescadores trasmalleros y aquellos que solo utilizan técnicas tradicionales lícitas; “...” El asesinato surge del entramado que se tejió entre la comunidad y el grupo armado ilegal" (Centro Nacional de Memoria Histórica, 2014). Es por eso, que la víctima no fue únicamente "Lucho", sus familiares, o sus colegas, sino, un grupo entero que defendía la pesca artesanal con el fin de proteger el medio ambiente y promover un estilo de pesca que respete el medio ambiente, pero, sobre todo, que esté pensada para brindarle un desarrollo sostenible a quienes viven de dicha actividad.

Ahora bien, esta clase de acontecimientos violentos son un efecto colateral de la guerra colombiana y del enfrentamientos que se han librado en zonas rurales como la región del Magdalena Medio, sabiendo lo anterior se puede establecer que los líderes sociales -que también son indispensablemente ambientales- quienes han sido asesinados de manera sistemática y de formas similares han debido encarar en su ejercicio social, las prácticas ilegales o usos inadecuados de los recursos naturales propios y aledaños, así como también se han encargado, por muchos años, de convivir con los intereses de los grupos subversivos ubicados en esos territorios.

Desafortunadamente el asesinato de Lucho partió en dos la organización de pescadores no solo la de APALL, sino la de las demás organizaciones pesqueras del Magdalena. Después de esto ha sido muy complejo retomar los procesos de participación y compromiso que alcanzó Lucho para que, por ejemplo, se evite el uso del trasmallo en la ciénaga. En este sentido,
“(...) el uso de los recursos hídricos para actividades económicas de mayor complejidad (como lo es la generación de energía eléctrica), ha cambiado la dinámica del territorio sin que las organizaciones sociales puedan tener una incidencia en este proceso, el cual se orienta por planes nacionales y regionales de mayor envergadura" (Castañeda et al., 2016, p. 9)

Según Castañeda et al., la puesta en funcionamiento de esta represa redujo el nivel de agua de la ciénaga y se afectó el equilibrio natural del ecosistema. Ante este panorama agregan que los factores que inciden en la generación de pobreza no han sido atacados como deberían, el desarrollo local ha tenido enfoques paternalistas y se han conformado con la generación de empleos de baja calidad, lo que empeora cuando reconocen que "los procesos organizados alrededor de la pesca y la acuicultura no logran concretar las iniciativas productivas de manejo sostenible de la ciénaga y en cuanto a la 
dimensión política, tampoco logran integrar al análisis la demanda existente contra Ecopetrol por contaminación” (Castañeda et al., 2016, p. 159).

En consecuencia, este tipo de dinámicas territoriales no pueden ignorarse o ser tratadas como males menores, pues sus impactos están enraizados en la comunidad, se reflejan en imaginarios, actitudes y comportamientos y, por tanto, repercuten de forma negativa en los procesos de resistencia que se efectúan para decidir sobre el tipo de desarrollo que se quiere en el territorio.

La cuestión ha sido cíclica, si se considera que el éxito económico y de vida está fuera del territorio, las personas que lo habitan disminuyen su sentido de pertenencia y esto impacta en actividades ancestrales como la pesca, ahora, si a esto se le suma que la producción de peces ya no es la misma de antes, por la contaminación de la ciénaga y los efectos de proyectos como el de la represa Hidrosogamoso, el desinterés de las personas por realizar esta actividad cada vez será mayor o lo que ha sido mucho peor, que las personas en aras de acaparar la mayor cantidad de pescado que les sea posible han optado por usar el trasmallo y pescar en tiempos de ceba, es decir cuando esta especie se está apareando para su posterior reproducción.

\section{Imaginarios sociales}

Como parte de los procesos que involucra el crecimiento de una sociedad, la renovación generacional y el contacto con diferentes medios, las comunidades consolidan a través de la historia y de los hechos a los cuales tienen que enfrentarse, una serie de concepciones frente a eso que les rodea. Así las cosas, los imaginarios sociales terminan siendo esquemas construidos que le permiten a los seres humanos en un contexto determinado explicar, percibir e intervenir respecto a una realidad concreta.

Así las cosas, Pintos (2005) expone que los imaginarios al ser esquemas poseen un elevado valor de abstracción que surge a partir de su reiteración en el tiempo, esto conlleva "referencias semejantes de percepción (espaciales, temporales, geográficas, históricas, culturales, religiosas, etc.), de explicación (marcos lógicos, emocionales, sentimentales, biográficos, etc.) y de intervención (estrategias, programas, políticas, tácticas, aprendizajes, etc.)" (Pintos, 2005, p. 43). En cuanto a la realidad, el autor es claro al sustentar que no hay una sola forma de ver las cosas y que hay múltiples realidades las cuales son permeadas por los procesos evolutivos.

Desde esta perspectiva los imaginarios se han convertido en una especie de nuevo lenguaje que configura otro conocimiento y a su vez, tienen una lógica de funcionamiento heurístico, lo cual permite que a partir de ellos se tomen decisiones o se hagan inferencias respecto a temas concretos de la realidad, por lo anterior, Randazzo (2012) expone que los imaginarios tienen la capacidad de influir en las maneras de pensar, decidir y orientar las acciones 
sociales una vez son formulados, legitimados y tratados como algo institucional.

Los imaginarios son percepciones individuales que con el tiempo y con su reiteración social, terminan siendo el reflejo de un pensamiento colectivo que interpreta la realidad y cuya aceptación lo convierte en algo generalizado, desde esta mirada se valida la necesidad de identificar y reconocer lo que un grupo de adolescentes y jóvenes del corregimiento El Llanito piensan hoy por hoy de la ciénaga que lleva este mismo nombre y la pesca artesanal alrededor de lo que para ellos ha significado el asesinato de Lucho Arango. Ahora bien, los imaginarios configuran y estructuran la realidad, pero no son un muro infalible, tal como lo mencionan Carretero y Ledrut citados por Randazzo, "los imaginarios no sólo se construyen y legitiman lo social, también lo deslegitiman y lo transforman (...) a través de su función desequilibradora" (Randazzo, 2012, p. 92). Entonces, el imaginario como fundamento, tiene que convertirse en ese punto de partida desde el cual se reflexione sobre las prácticas individuales y colectivas que inciden en los espacios que se habitan y cómo su reconocimiento termina abriendo escenarios de diálogos para asignar nuevos sentidos sobre lo que ocurre en el territorio.

\section{Comunicación y cambio social}

Las problemáticas territoriales descritas hasta el momento y su relación con la conformación de imaginarios en las poblaciones locales, no ocurren solamente en El Llanito, estas situaciones se repiten de forma distinta en otros territorios del nivel nacional e internacional, pero, a pesar de estas prácticas nocivas, por iniciativa de las comunidades y con el respaldo de diferentes organismos, se han implementado experiencias para la protección de los ecosistemas hídricos y promoción de la pesca artesanal como una técnica de extracción responsable con el medio ambiente.

A nivel internacional se desarrolló el proyecto "Comuniquemos la importancia de los manglares para aumentar nuestra resiliencia a los efectos negativos del cambio climático", el cual fue llevado a cabo en dos comunidades costeras de Cuba. Las personas que participaron en este proyecto fueron jóvenes, quienes recibieron capacitaciones técnicas de cuidado relacionadas con el medio ambiente y a su vez, fueron formados en la generación de contenidos audiovisuales para elaborar diferentes piezas comunicativas, las cuales fueron usadas para enseñarle a otros lo aprendido y la relevancia que tiene para la comunidad cuidar sus manglares.

Ahora bien, en la comunidad de El Llanito se ejecutó el proyecto de López (2020), "Pescando historias. Memorias de un llanitero" iniciativa que a través del trabajo colaborativo con estudiantes y orientado por prácticas pedagógicas propias de la educomunicación, formó a un grupo de adolescentes y jóvenes en tres herramientas de comunicación: fotografía, 
podcast y audiovisual participativo. Lo anterior, con la intención de sensibilizar a la población juvenil sobre las problemáticas que vive el territorio y las implicaciones que esto tiene para la sostenibilidad del mismo. Este proyecto tuvo como sustento sus imaginarios, pues consideró que las ideas arraigadas en la población son justamente, la piedra angular desde la cual se deben empezar a deconstruir las ideas que han pregonado un desarrollo insostenible para los ecosistemas y el deterioro de sus legados ancestrales, así López (2020) sostiene que, "a un territorio lo hace su memoria, esa que se trasmite de generación en generación a pesar de lo dolorosa que resulte ser, porque es de esta manera que se impacta en la apropiación de una identidad territorial y del orgullo que siente por su cultura" $(s p)$.

Estos procesos de comunicación para el cambio social han tenido éxito en la medida en que han involucrado desde el principio a las comunidades, reconocen su cultura, su contexto y desde allí se construyen de forma colaborativas las propuestas de intervención, así las cosas, cobra especial importancia lo expuesto por Cadavid (2006) citada por Sotelo (2011) cuando menciona que hay que partir de la observación de las carencias y las posibilidades, al igual que de la cultura y los imaginarios. Por consiguiente, los enfoques de paz territorial y transformación de conflictos se erigen como paradigmas fundamentales para empezar a resolver las verdaderas causas de la guerra en Colombia. En consecuencia, la comunicación para el cambio social al comprender que las comunidades no son una masa inanimada, sino que son movimiento y que se constituyen por personas que sienten, creen, y piensan, tienen el poder de reconocer sus problemáticas y poner en marcha soluciones colectivas que les ayuden a transformarlas.

Teniendo en cuenta lo descrito, se hace preciso recordar que este artículo concentra sus esfuerzos en describir los imaginarios que tiene la población juvenil de El Llanito y evidenciar cómo es que estas concepciones frente al lugar que habitan, sino reciben la atención que ameritan, seguirán siendo un alimento bien sea para sostener los conflictos que ya existen o para favorecer la aparición otros distintos.

\section{Metodología}

El proyecto de investigación tuvo un enfoque cualitativo dentro de su diseño metodológico, con un alcance de estudio exploratorio, dado que busca "examinar un tema o problema de investigación poco estudiado, del cual se tienen muchas dudas o no se ha abordado antes" (Hernández, Fernández y Baptista 2014, p. 91), así mismo, reconocer los imaginarios y los significados que a través del tiempo adolescentes y jóvenes del corregimiento El Llanito, le han asignado al territorio, la ciénaga, Lucho Arango y a la pesca artesanal, constituye esa realidad susceptible de ser investigada y comprendida desde una perspectiva cualitativa, puesto que el propósito de este enfoque "es 
construir la realidad, descubrirlo, interpretarlo; por tanto el método no es la verificación, la contrastación o falsación popperiana, sino la comprensión, la interpretación o la hermenéutica” (Ñaupas et al., 2013, p. 98).

Desde este ángulo, el enfoque cualitativo se concentra en estudiar los elementos, características o particularidades que le dan sentido a una realidad específica, de allí que este tipo de enfoque no se limita a los resultados, sino que deposite un grado especial de importancia en el proceso, pues son los sujetos o grupos de estudio quienes desde su experiencia pueden describir y explicar los fenómenos y/o acciones a partir de los cuales le asignan sentido a su realidad.

Las técnicas cualitativas usadas para recopilar los imaginarios de los jóvenes y adolescentes responden a la implementación de la entrevista abierta de tipo semiestructurada y al desarrollo de grupos focales. Con esto se posibilitó el análisis de los comportamientos sociales propios de la interacción entre las personas que conforman la comunidad de El Llanito y de forma posterior esclarecer cómo se relacionan con los retos que es necesario abordar para construir paz con enfoque territorial.

Por medio de la conversación cara a cara que es propia de las técnicas dialógicas, los participantes de la investigación expresaron las opiniones y percepciones que tienen sobre el fenómeno de estudio. En este sentido la entrevista brinda la posibilidad de profundizar la información con cada uno de los sujetos seleccionados, tal como señala Patton (1980) citado por Gaitán y Piñuel, (1998) la entrevista es una fuente que permite describir e interpretar aspectos de la realidad que no son directamente observables como sentimientos, percepciones y creencias, así como hechos del pasado que se han quedado en la memoria de las personas.

Aunque la entrevista recopila expresiones individuales, estas hacen parte de una realidad cotidiana que representan los estilos de vida de las personas, pues con esta se pretende que "a través de la recogida de un conjunto de saberes privados, se dé la construcción del sentido social de la conducta individual o del grupo de referencia de ese individuo" (Alonso, 1995, p. 228).

Así mismo, se recurrió a la técnica del grupo focal ubicada dentro de lo que se denomina grupos de discusión, donde se buscan obtener conocimientos sobre la realidad social del objeto de estudio por medio de las personas que integran el grupo. La relación que existe entre esta técnica y la entrevista abierta es que son complementarias, pues según Alonso (1998), "en los grupos de discusión lo que obtenemos son siempre representaciones de carácter colectivo", (p. 227) que dan paso para que el investigador pueda contrastar la información individual que se obtiene en la entrevista que, en este caso, serán los imaginarios frente a la pesca artesanal. 
Esta técnica recurre a la formación de grupos artificiales de tipo reflexivo entendiéndose como "los que se detienen en el análisis de las interacciones comunicativas conversacionales, de modo que, en su desarrollo y resultados, sirven a la estimación, análisis, y evaluación de fenómenos sociales concretos, a la resolución de problemas o a la adopción de decisiones" (Gaitán y Piñuel, 1998, p. 89).

De manera que, se realizaron tres grupos focales integrados por adolescentes y jóvenes que están vinculados a la Institución Educativa San Marcos. En total participaron 68 estudiantes de los cuales, 31 fueron hombres y 37 mujeres; a su vez realizaban estudios de primaria, secundaria y/o ya eran egresados de la institución. Es importante precisar que el colegio San Marcos es el único plantel educativo que hace presencia en El Llanito y está integrado por cuatro sedes en la zona rural, sin embargo, por cuestiones de desplazamiento este proyecto solo trabajó con la sede principal que se encuentra en el centro poblado del corregimiento.

Gráfico 1. Participación por género y nivel de formación

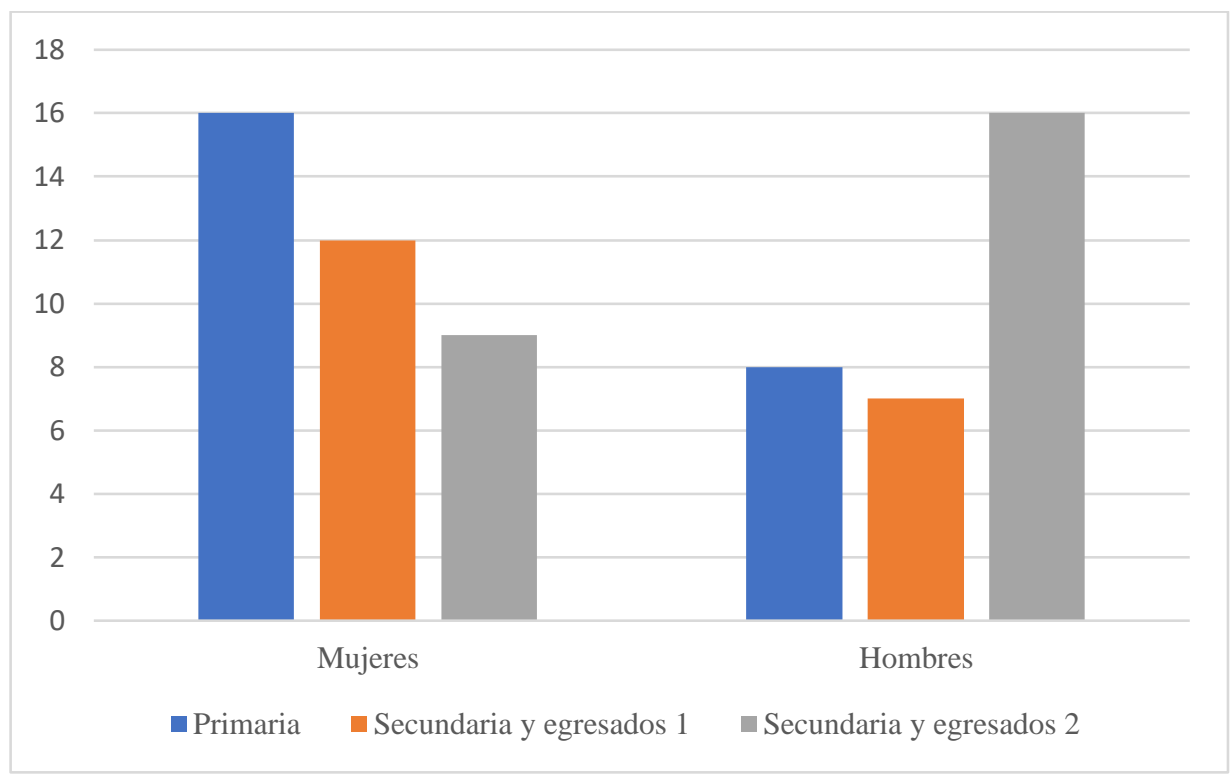

Fuente: Elaboración propia.

Las preguntas en cada uno de los instrumentos, estuvo desagregada por categorías. Los grupos focales estuvieron mediados por el uso de metodologías participativas propias de la educomunicación con las cuales se buscó eliminar la verticalidad de los encuentros y abrir las posibilidades para descubrir en colectivo. De esta forma, los estudiantes que participaron no se limitaban a dar respuestas, sino que también analizaban su realidad y plasmaban sus ideas en cartografías, escritura de historias y composiciones artísticas. En total hubo 25 preguntas en cada instrumento y debido al tipo de técnicas escogido, los investigadores de acuerdo con la dinámica del encuentro agregaron nuevos cuestionamientos. 
En cuanto a la categoría de territorio se buscó que los jóvenes y adolescentes hicieran un reconocimiento del corregimiento a través de un acercamiento a la cartografía, en la que a partir de convenciones identificaron lugares importantes, agradables, peligrosos, personas importantes y amenazas de la ciénaga; sobre Lucho Arango, se buscó que las personas participantes establecieran un concepto frente a qué significa ser líder social y ambiental y que través de la elaboración de historias se reconstruyeran sus conocimientos sobre el pescador Luis Alberto Arango; respecto a la pesca artesanal su interés estuvo centrado en establecer qué conocimientos tenían sobre la actividad, sus técnicas, las historias de los pescadores más representativos y su sentido de identidad con el tema; y en relación a la ciénaga, determinar los espacios más representativos de la ciénaga El Llanito y que reflexionaran sobre los daños medio ambientales que ha sufrido este cuerpo hídrico durante los últimos años.

\section{Resultados}

Los imaginarios para cada una de las categorías revisadas dan cuenta de concepciones trasmitidas de generación en generación y que, entre otras cosas, son el resultado de ideas propias del modelo económico neoliberal que ha impulsado las brechas de desarrollo entre el campo y la ciudad, lo que aumentan el desarraigo de los habitantes hacia las zonas rurales dado que todavía se cree que el éxito está contenido en las grandes ciudades.

\section{Relación de imaginarios sobre el territorio}

Cuadro 1. Imaginarios sobre el territorio.

\begin{tabular}{|l|l|}
\hline \multicolumn{1}{|c|}{ Convención } & \multicolumn{1}{c|}{ Ideas/comentarios } \\
\hline Espacios agradables & $\begin{array}{l}\text { "La cancha"; "El puente"; "La isla de los Mangos porque allá nos } \\
\text { podemos bañar"; "La ciénaga". }\end{array}$ \\
\hline $\begin{array}{l}\text { Personas y espacios } \\
\text { peligrosos }\end{array}$ & $\begin{array}{l}\text { "La ciénaga es peligrosa porque nos podemos ahogar"; "Faber se } \\
\text { vuelve loco cuando consume"; "Las cantinas porque pueden haber } \\
\text { peleas, con pistola, botellas"; "Faber es un peligro porque cuando se } \\
\text { mete sus trabas puede hacernos daño"; "La isla de los Mangos es } \\
\text { peligrosa porque hay lugares donde aprovechan para robar". }\end{array}$ \\
\hline Zonas divertidas & $\begin{array}{l}\text { "El puente, porque turista o persona que no se tome una foto en El } \\
\text { puente no vino a El Llanito"; "La cancha de futbol y el parque } \\
\text { podemos jugar con nuestros amigos". }\end{array}$ \\
\hline $\begin{array}{l}\text { importantes } \\
\text { Enemigos de la }\end{array}$ & $\begin{array}{l}\text { "En la iglesia podemos aprender sobre Dios"; "La ciénaga es } \\
\text { importante porque nos da la comida, el agua, casi todo"; "Las } \\
\text { personas importantes son los miembros de la Junta de Acción } \\
\text { Comunal"; "El puesto de salud y el colegio también son } \\
\text { importantes". }\end{array}$ \\
\hline $\begin{array}{l}\text { "La cancha es una amenaza porque nosotros botamos basura, } \\
\text { "Nosotros mismos somos los que dañamos la ciénaga porque algunos } \\
\text { hacen trasmallo, botamos basuras y contaminamos"; "Los derrames } \\
\text { de petróleo". }\end{array}$ \\
\hline
\end{tabular}

Fuente: elaboración propia 
En total se realizaron 15 cartografías en las que se reconoció la presencia gráfica de la ciénaga, la cancha, algunas tiendas, la carretera principal y lugares como El típico ${ }^{2}$. A su vez, la iglesia fue un elemento común en todas las cartografías realizadas, lo cual permite afirmar que, para los jóvenes del corregimiento esta institución eclesiástica es fundamental dado que la identifican con las convenciones de lugares agradables y espacios importantes, por lo que se infiere que la iglesia no es solo un punto de referencia geográfico, pues también mantiene un grado de valor simbólico e importante, debido a las prácticas culturales del pasado que aún permanecen en sus habitantes.

Por otra parte, encuentran El Típico como un lugar divertido donde pueden bañarse y disfrutar de la ciénaga, sin embargo, reconocen los peligros contaminantes que se localizan en la zona por los diversos daños ambientales que han causado los desechos y los tubos de petróleo; lo cual representa una paradoja porque desde Randazzo (2012), se expone que los imaginarios tienen la capacidad de influir en las maneras de pensar, decidir y orientar las acciones sociales una vez son formulados, legitimados y tratados como algo institucional, dando explicación al poco interés e identidad con la ciénaga.

Algo que es importante mencionar en este punto es que los imaginarios sobre cada categoría se cruzan y en este sentido, cuando se aborda el territorio, el grupo de participantes reconoce a la ciénaga con un elemento importante en su composición, así, determinaron que las principales amenazas para esta eran la contaminación ocasionada por derrames de petróleo, la pesca con trasmallo, las basuras y la presencia de animales peligrosos, pero la que más se repitió fue la ocasionada por los residuos sólidos. Es importante destacar que los jóvenes son conscientes que muchos de los desechos llegan al agua por la mala disposición que le dan los habitantes, afirmando que "nosotros mismos somos los que dañamos la ciénaga porque algunos hacen trasmallo, botamos basuras y contaminamos", sin embargo esta comunidad sabe que el recurso hídrico es parte importante para la economía del lugar "la ciénaga es importante porque nos da la comida, el agua, casi todo", así, los estudiantes no están realizando ningún tipo de labor en pro del buen mantenimiento de su principal fuente hídrica y económica, evidenciando que, aunque reconocen su importancia no tienen un sentido de pertenencia.

\section{Relación de imaginarios sobre Lucho Arango}

Previo al reconocimiento del imaginario sobre Lucho Arango y teniendo en cuenta el papel que jugó no solo como pescador sino como líder social y ambiental, se realizó la construcción colectiva del significado alrededor de esta palabra compuesta y desde allí profundizar en las concepciones, ideas, expectativas y prácticas que se asociaran a las personas que desempeñan este papel en las comunidades. En el siguiente gráfico se relaciona algunas de las

\footnotetext{
${ }^{2}$ Restaurante tradicional del corregimiento que se destaca por estar ubicado a orillas de la ciénaga.
} 
definiciones que construyeron los distintos grupos que hicieron parte del proceso.

Diagrama 1. Síntesis sobre líderes sociales-ambientales

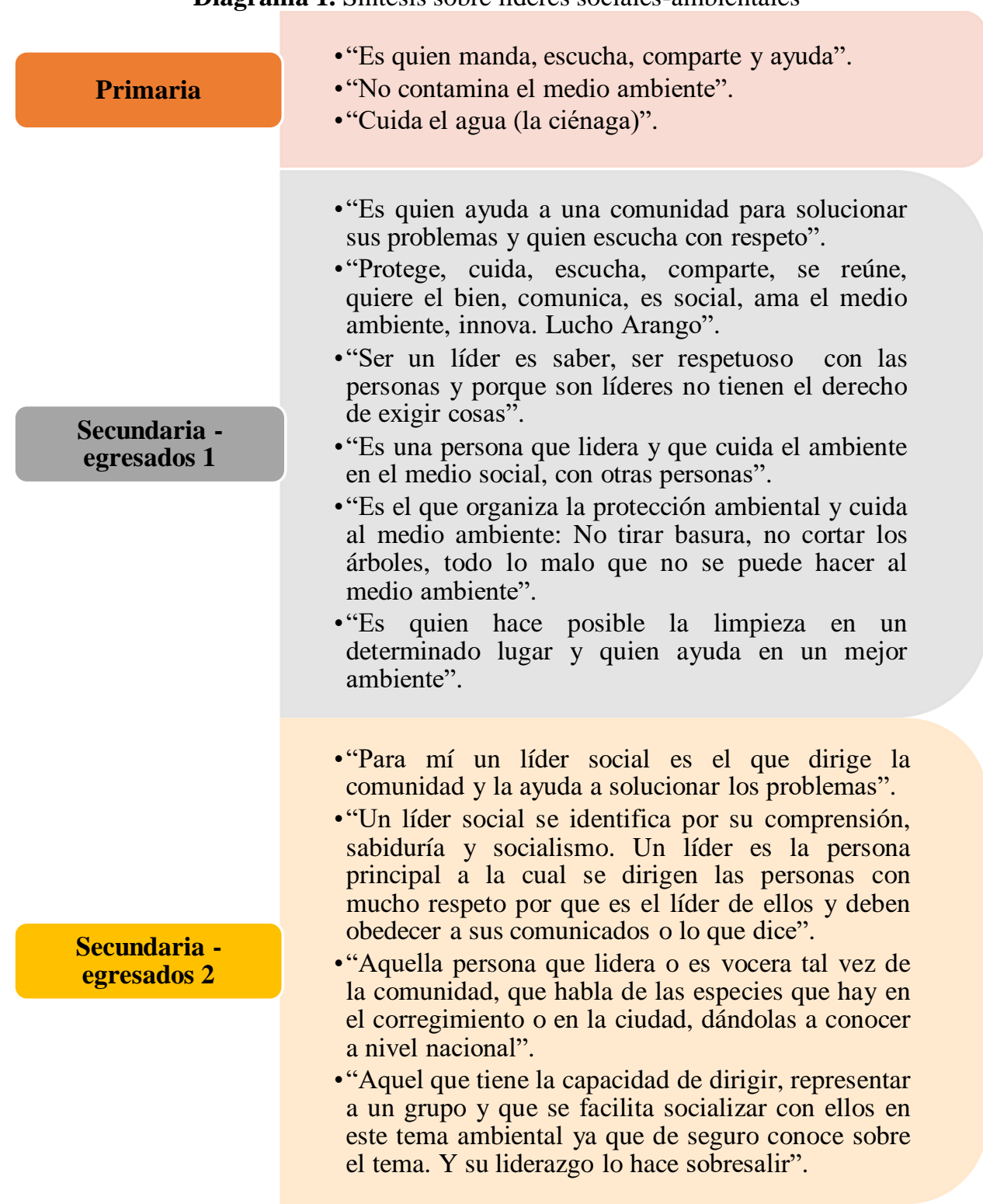

Fuente: elaboración propia.

Según la Organización de las Naciones Unidas (ONU, 1998), en conjunto con el Gobierno Nacional, un líder social se identifica y se caracteriza por ser "una persona, organización o colectivo que se esfuerza por promover y proteger los derechos", en cuanto a lo que significa ser un líder socio-ambiental, teniendo de referente la definición anterior, es alguien que centra sus actividades en un sector geográfico particular al que pertenece y está enfocado en la preservación de todo un ecosistema, como también, del autosostenimiento de los ecosistemas y que visualiza mecanismos de protección que favorezcan el trabajo comunitario. 
En este sentido, los niños de primaria del Instituto San Marcos definen a un líder social-ambiental como "una persona o un grupo de personas que están a cargo del cuidado del medio ambiente porque quiere proteger a sus amigos, familia, a su pueblo (comunidad)". Por otra parte, el segundo grupo mantiene la idea respecto a que puede ser una persona, pero también una organización que quiere el bien de su comunidad como lo hacía Lucho Arango y enfatizan en que él fue un hombre que compartía con todos, su amor por El Llanito y el medio ambiente. Así mismo se extrae de sus ideas la importancia respecto a que el líder trasmita la sensación de protección.

En el tercer grupo parecen madurar las anteriores reflexiones y se ratifica su vocación de servicio del líder, pero se menciona la responsabilidad que tiene cada persona para abordar el cuidado de su entorno, por ello, se explica que desde estos liderazgos se promueven los deberes para proteger el medio ambiente. Aunque consideran que es importante que un líder social se preocupe por el medio ambiente, reconocen que esa no ha de ser su única función, ya que comienzan a aludir a sus labores temas de derechos humanos, la conformación y la movilización de grupos de trabajo en cuanto a problemáticas en el territorio, la búsqueda de soluciones ante necesidades conjuntas.

Diagrama 2. Asociaciones sobre Lucho Arango

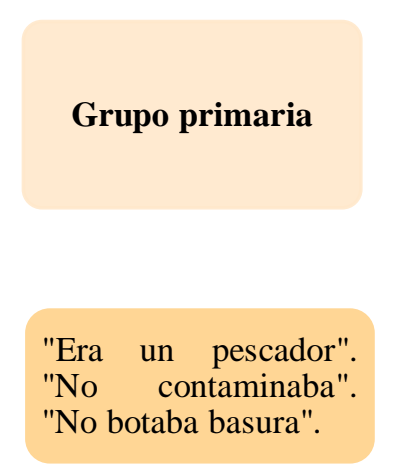

"Se integraba con la comunidad, era buen amigo y sobre todo era pescador".
Grupo secundaria egresados 1 y 2
"Lucho Arango fue un gran líder, él se levantaba desde las tres de la madrugada a patrullar hasta que un día lo mataron. El Llanito dejó de ser el mismo de antes ya no se levantan a patrullar como lo hacía Lucho, patrullar era como levantarse a ver si había trasmallo".

Lider muy respetado. Velaba por los derechos de los pescadores. Estaba en contra de la pesca ilícita en la ciénaga. Lo mataron. Era de APALL. Hacía patrullaje contra el trasmallo. Cuidaba, ayudaba y luchaba.

Fuente: elaboración propia.

Ahora bien, respecto a Lucho Arango en el grupo de primaria se evidencia poca profundización acerca de quién era y qué hacía "Lucho" pues, la mayoría de los niños y niñas solo le identifican como un "un pescador de la 
zona que habían asesinado", más no por el trabajo y trayectoria social que le distinguía en el corregimiento, sin embargo, aparecen algunas ideas que el reconocen como un hombre "que se integraba con la comunidad, que era buen amigo y sobre todo que era pescador".

Por el contrario, en los grupos integrados por estudiantes de secundaria y egresados, recuerdan a Lucho por la labor que emprendía en cuanto a la limpieza de la ciénaga, "se levantaba a las dos de la mañana a salir a limpiar la ciénaga y la calle para que estuviera más limpia” y hacen énfasis en que él madrugaba a patrullar en los alrededores del recurso hídrico. Respecto a su muerte esta fue catalogada por ellas y ellos como un asesinato. Perciben que toda la comunidad de El Llanito sintió su ausencia, puesto que en algunos de las historias narradas usan un vocabulario con cierta intensidad de carácter emocional, haciendo comentarios como, "los monstruos que lo mataron", "El Llanito quedó destruido como hijo sin padre", "se sintió un dolor en familia, amigos y comunidad", "y ahora la ciénaga de El Llanito quedó contaminada" y "la ciénaga lloró por su protector" entre otros. En consecuencia, la muerte de Lucho evoca la pérdida de la esperanza frente a lucha contra las amenazas de la ciénaga.

Es interesante destacar que, dentro de las construcciones de tipo narrativo, está siempre vigente el tipo de muerte que tuvo Lucho Arango, las descripciones que hacen los chicos y jóvenes, sobre todo, denotan un voz a voz a cerca de los hechos que envolvieron ese 12 de febrero del 2009; sin embargo, no hay claridad frente a quienes son los actores armados que acaban con la vida del líder social y esto también se infiere, porque solo una joven identifica al ELN como la organización responsable. No obstante, según las investigaciones del Estado, los responsables es una Bacrim conocida como Los Rastrojos (Semana, 2017).

Lucho Arango es visto todavía como el actor social, líder ambiental y llanitero que se situó en el territorio un día y para siempre, sabiéndose defensor y protector de un sustrato que él reconocía vivo y al comprender ese detalle, reconocía que la relación con este ente natural debía ser mutualista, pues de ese lugar dependía su supervivencia y la de sus colegas, familiares y amigos. Algunas personas resaltan el hecho de que Lucho les comunicaba a las personas la importancia de proteger la ciénaga; inclusive un joven menciona que "Lucho le decía a la gente que cuidaran la ciénaga que no dejarán de cuidarla porque la ciénaga sería el principal centro de admiración".

Las narraciones se caracterizan por el uso frecuente "cuidar, limpiar, patrullar" para referirse al papel que desempeñó Lucho. Mencionan que las personas acudían a Lucho ante cualquier problemática entorno a la ciénaga o la pesca; asimismo, han escrito que Lucho comienza a conformar un grupo, lo cual significa que reconocen este factor como una característica de su 
liderazgo. En consecuencia, identifican a Luis Arango como algo más que un pescador, para ellos es un héroe, un emprendedor, un innovador.

Sin embargo, un hecho que llega a llamar la atención es que, pese a que conocen lo que él hacía (como ser el vigía de la ciénaga, el tema de las basuras, entre otras cosas), no se evidencia que los chicos participen activamente en actividades de este tipo. En este sentido, si se logra generar en los jóvenes un interés en cuanto a proseguir con las actividades entorno al cuidado de la ciénaga, realizadas en su momento por Lucho Arango, es más factible que en el futuro, sea posible la existencia y permanencia de una cultura de paz en el territorio.

\section{Relación de imaginarios ciénaga - medio ambiente}

Por otra parte, en cuanto a sus imaginarios sobre la ciénaga como ya quedó evidenciado en la categoría anterior, esta termina siendo un eje central para reconocer el liderazgo de Lucho y relacionarse por consiguiente con la pesca artesanal, así, la técnica del trasmallo es reconocida como una de las de mayor riesgo para la ciénaga, el cual atenta contra la reproducción de los peces, pero señalan que ya es normal ver esta situación, debido a que muchas personas no acatan las normas; a su vez identifican la contaminación por desechos orgánicos que dejan los turistas e incluso las personas de la comunidad y la pérdida de peces y fauna como otras de las amenazas para este recurso hídrico.

En cuanto a los últimos daños ambientales que ha ocurrido sobre la ciénaga, reconocen que han sido el derrame de petróleo, la muerte de peces y el vertimiento de aguas residuales.

El cuidado del medio ambiente en el corregimiento es mínimo, pues pocas personas han estado dispuestas a realizar una verdadera protección de sus recursos, de allí que solo algunos pescadores, profesores del colegio y líderes de la Junta de Acción Comunal, sean los que realicen acciones para fomentar el cuidado y el uso responsable de los recursos naturales.

Ahora, si bien en algún momento mencionan las campañas de empresas como Hidrosogamoso, hay que dejar claro que dichas acciones corresponden a las establecidas por ley, para que estás organizaciones cumplan con su responsabilidad social ambiental, lo cual, en la mayoría de los casos, va en directa proporción con los impactos negativos que las mismas actividades económicas que estas realizan, ocasionan sobre los territorios.

Una situación que evidencian las personas participantes es que, al no contar con un sistema adecuado para el manejo de las aguas residuales, estas tienen su disposición final en los diferentes cuerpos hídricos que están alrededor del territorio; además los residuos sólidos se vertían a la ciénaga dado que no 
contaban con un servicio de recolección de basura, sin embargo, después de un tiempo un camión hace un recorrido por los diferentes barrios para recolectar estos desechos. Respecto a los proyectos ambientales que se han desarrollado en El Llanito, comentan que hay apatía por parte de algunas personas de la comunidad para cooperar con los líderes y pescadores que luchan por la preservación de su ecosistema haciendo actividades de recolección de residuos orgánicos en la ciénaga, además de campañas de concientización de la población.

Poco a poco la Institución San Marcos ha realizado actividades con sus estudiantes y ha fomentado su participación a través del Grupo Ecológico, enseñándoles aspectos fundamentales sobre el medio ambiente, posiblemente sea esta la principal fuente para que los niños, niñas, adolescentes y jóvenes, tengan algún conocimiento frente al cuidado medio ambiental. No obstante, en el análisis de sus respuestas se puede inferir que, por ahora, la protección ambiental termina siendo solo un discurso, pues en los relatos no se identifican prácticas incorporadas a su vida diaria que aporten en este propósito $\mathrm{y}$, por el contrario, su participación se limita a eventos y/o actividades.

En cuanto a los últimos daños ambientales y los riesgos que amenazan este recurso hídrico, consideran que la extracción de petróleo ha ido contaminando las especies que habitan en la ciénaga, ya que en varias ocasiones los peces han muerto por la presencia de crudo en el agua, de allí que mencionen lo ocasionado por el derrame en el pozo Lizama 158.

Lo anterior también repercute de forma negativa en la realización de la pesca, pues el trabajo y sustento de los pescadores depende del buen estado de los pescados. Así mismo exponen que la contaminación, entre ella por desechos en la ciénaga tirados por habitantes y turistas, los cambios climáticos (intensos periodos de verano) y la pesca no controlada, han ocasionado la disminución de fauna, flora y los bajos niveles de agua de la ciénaga.

En consecuencia, la pesca artesanal se ha visto afectada seriamente en los últimos años, debido a causas como las descritas anteriormente, la poca renovación generacional y a la puesta en funcionamiento de la represa Hidrosogamoso, pues con esta, los pescadores deben sembrar los peces en la ciénaga, dado que el sistema de vida y reproducción de la especie cambió y por las alteraciones en los cauces del agua no se da de forma natural. 


\section{Relación de imaginarios pesca artesanal}

\begin{tabular}{|c|c|c|}
\hline Primaria & Secundaria - egresados 1 & Secundaria - egresados 2 \\
\hline $\begin{array}{l}\text { "Es algo artesanal de aquí de El } \\
\text { "Llanito". } \\
\text { "Sé pescar con anzuelo". } \\
\text { •"No me veo como pescador, a } \\
\text { mí eso me parece aburrido". } \\
\text { •"Salen a pescar en las tardes y } \\
\text { regresan a la media noche". } \\
\text { "Muchas veces salen a pescar y } \\
\text { llegan a casa sin nada". } \\
\text { "La vida de los pescadores es } \\
\text { muy difícil, porque a veces los } \\
\text { pescados no quieren salir, los } \\
\text { animales más grandes los } \\
\text { espantan". } \\
\text { "Es difícil porque a veces no } \\
\text { hay pescado". } \\
\text { "Ellos se levantan muy } \\
\text { temprano y despues tienen } \\
\text { sueño cuando están pescando". }\end{array}$ & $\begin{array}{l}\text { "Pienso que las personas que } \\
\text { no estudian son los que se } \\
\text { dedican a eso" } \\
\text { "Es la forma en que se puede } \\
\text { conseguir el alimento". } \\
\text { "No me dedicaría a la pesca } \\
\text { artesanal porque tengo la } \\
\text { solvencia económica para } \\
\text { dedicarme a otra cosa. Sin } \\
\text { embargo, la pesca es vista } \\
\text { como una oportunidad para el } \\
\text { turismo para personas de otros } \\
\text { lugares, como una pesca } \\
\text { recreativa. } \\
\text { "Preferiría trabajar en } \\
\text { construcción que ser pescador } \\
\text { porque en ir a pescar se } \\
\text { trasnocha uno mucho y se tiene } \\
\text { que parar temprano, en cambio, } \\
\text { en construcción se puede uno } \\
\text { levantar a la hora que quiera, } \\
\text { puede desayunar". } \\
\text { - Con la pesca artesanal pueden } \\
\text { crear ustedes su misma } \\
\text { empresa, porque ustedes } \\
\text { mismos no pueden ir a pescar, } \\
\text { sino que otra gente del país } \\
\text { puede venir a hacer eso, }\end{array}$ & $\begin{array}{l}\text {-Un pescador artesanal es aquel } \\
\text { que utiliza elementos hechos } \\
\text { por él mismo nativos de la } \\
\text { región, sin importar que sea } \\
\text { legal o ilegal, porque ya eso es } \\
\text { el arte. Lo que se califica como } \\
\text { legal o ilegal es el uso que yo le } \\
\text { doy a eso artesanal que yo } \\
\text { hago". } \\
\text { "Si hubiésemos querido ser } \\
\text { pescadores no estuviéramos } \\
\text { estudiando". } \\
\text { "La mentalidad de nosotros } \\
\text { ahora es salir a estudiar y traer } \\
\text { algo que beneficie al } \\
\text { corregimiento y a la } \\
\text { comunidad, ser líderes sociales, } \\
\text { líderes ambientales, algo que } \\
\text { beneficie y contribuya al } \\
\text { desarrollo de la comunidad". } \\
\text { "La economía base del } \\
\text { corregimiento es la pesca, } \\
\text { entonces así tengamos una } \\
\text { relación directa o indirecta la } \\
\text { tenemos, porque nuestros } \\
\text { familiares son pescadores, } \\
\text { venden, comercializan el } \\
\text { producto, consumimos el } \\
\text { producto en los restaurantes en } \\
\text { nuestras casas, entonces si } \\
\text { tenemos una relación con la } \\
\text { pesca así no la practiquemos" }\end{array}$ \\
\hline
\end{tabular}

Fuente: elaboración propia

Las personas participantes manifiestan que en algún momento han estado en contacto con la pesca artesanal ya sea porque algún familiar la realiza o porque la han practicado por cuenta propia. En este sentido, reconocen que tienen claridad frente a las consecuencias que ocasionan las herramientas ilícitas de pesca como el trasmallo. Paralelo a esto, resaltan algunas acciones que favorecen la pesca lícita como el pescar día por medio o cuando las especies no estén en ceba, así mismo, hacer patrullaje para quitar todos los elementos que son prohibidos y cuyo uso afecta el ecosistema de la ciénaga. En cuanto al reconocimiento de la pesca artesanal, en el caso de los niños de primaria, los significados asociados al término no son claros, algunos creen que es atrapar peces usando cualquier técnica de pesca y solo unos pocos encuentran diferencia entre herramientas como la atarraya y el trasmallo; en cuanto a los de secundaria y egresados, la situación no es distinta, persiste la confusión pero con un imaginario permeado por estereotipos, respecto a quienes se dedican a la pesca artesanal, ya que lo relacionan con personas que no quieren o no pueden estudiar.

Frente al relacionamiento o cercanía con la pesca, sus ideas resultan controversiales, en los chicos de primaria se observó que la realización de 
esta actividad es motivada por intereses como el distraerse y aprender, por su parte, los más grandes tienen un acercamiento frente al tema y alguna vez en su vida han realizado actividades de pesca con la ayuda de un mayor de edad, pero no todos se sienten identificados con ella, sin embargo, comentan que el hecho de vivir en el corregimiento ya los hace tener una relación con todo el tema de pesca. Su imaginario no está dado por una definición académica frente a lo que significa la pesca artesanal, sino que parte principalmente de las experiencias que han vivido practicando esta actividad.

De acuerdo con lo anterior, es importante resaltar el ideal que tienen los jóvenes del corregimiento frente al tema de ser pescadores a futuro, en este punto, la edad juega un papel fundamental puesto que las referencias semejantes de explicación, percepción y de intervención, descritas en el marco teórico, poseen un alto poder de abstracción en la creación de esquemas y, por lo tanto, también de imaginario, por lo cual, su nivel educativo incide en la formación de sus proyectos de vida, es aquí donde permea la importancia social y económica del sector pesquero. Se percibió que llegar a ser pescadores no es algo que esté contemplado como un ideal de vida; sin embargo, sí resaltan la responsabilidad que tienen con la preservación y protección de los recursos naturales, tanto así, que consideran que siendo profesionales en otras áreas les permitirá contribuir con el desarrollo económico y sostenible del corregimiento, ya que perciben la pesca artesanal como una fuente de ingreso, pero desde el turismo.

En relación con el diario vivir de un pescador, los tres grupos coinciden en la misma opinión, consideran que es un trabajo duro y de arduas horas que en algunas ocasiones les implica salir de casa por varios días, mientras que manifiestan el descontento con el que viven los pescadores, debido a que en la actualidad la cantidad de peces es escasa y los cambios en la ciénaga son muy notorios, tanto así, que en ocasiones llegan a casa sin ni siquiera lo del sustento diario.

Por lo anterior, ser futuros pescadores no es una profesión que llame la atención, sin embargo, respetan dicho trabajo y ven altas proyecciones con el arte de pesca, la cual mejoraría la economía de muchas familias dedicadas a ello. Así que es importante tener en cuenta este aspecto para la creación de la estrategia, ya que los chicos tienen un grado de interés alto con el mejoramiento económico de su corregimiento.

Frente a los enigmas que confronta la pesca artesanal en El Llanito, concuerdan al mencionar aspectos pertinentes en el ítem, como lo es una práctica que no es correcta al momento de ejercer la labor: el uso del trasmallo. Y, sobre todo, hacen énfasis en la contaminación del agua de la ciénaga, que termina siendo lo más observado en su cotidianidad, pues las heces humanas y animales muertos que son arrojados por la comunidad les resultó como un impedimento para el espacio de la recreación en las aguas. 
Por último, el grupo de investigadores buscó saber el conocimiento que tienen los grupos sobre proyectos de pesca por parte de entidades públicas, pero este fue casi nulo, a salvedad de un niño del primer grupo de secundaria, que mencionó a APALL, el cual describe como: "la asociación de todos los llaniteros que se encarga de vigilar y hacer guardias", y conoce de ello debido a que personas de su núcleo familiar son cercanas al programa. Frente al tema, un niño de primaria recuerda a ISAGEN porque tuvo contacto en una actividad que consistía en el cuidado de medio ambiente, aprender a poner bolsas. Con esto, se distingue un desconocimiento y/o posible abandono por parte del Estado en el fomento y control de las garantías que permitan la preservación y el desempeño óptimo del arte pesquero.

\section{Conclusiones}

Mucho se ha hablado sobre la necesidad de abandonar las armas para terminar con el conflicto en el país, pero lo cierto es que dicho accionar solo ha dejado de manifiesto que las raíces de la guerra en Colombia son bastante profundas y que estas obedecen en gran medida a la insatisfacción de necesidades básicas, al fuerte abandono estatal y a los micropoderes implementados por los diversos actores armados en lo local. En consecuencia, los procesos de construcción de paz, no se pueden seguir mirando desde la superficie para apagar el fuego que ocasiona la violencia directa, sino que requiere de esfuerzos mayores para revisar al interior de las comunidades por esas ideas o esos dispositivos arraigados en el colectivo, que facilitan la permanencia o aparición de nuevos conflictos.

En ese sentido, los imaginarios inciden de forma directa sobre el tipo de prácticas que se realizan, estás pueden ser públicas, privadas, sociales o individuales (Fernández, 1997), pero en cualquier circunstancia, factores como los modelos de desarrollo, las ideologías, la política, la cultura, entre otros, inciden en la formación de dichas ideas. De alguna forma el proceso de formación, pero también de interacción con ese imaginario es una cuestión cíclica que como bien explica Castoriadis (1997) le asignan sentido y representan el mundo, haciendo que el ámbito social permita su institucionalización. Así, los imaginarios no son una ficción, sino que son las estructuras o construcciones de apariencia colectiva desde las cuales las personas se relacionan entre ellas mismas y con los dispositivos de su entorno. Desde esta perspectiva, Pintos (2004) considera que los imaginarios tienen la función de promover una imagen de estabilidad frente a la fragmentación y las relaciones sociales variantes, "generar percepciones de continuidad en experiencias discontinuas, proporcionar explicaciones globales a los fenómenos fragmentarios y permitir intervenir en los procesos construidos desde perspectivas diferenciadas" (D’Agostino, 2014, p. 132).

En consecuencia, al indagar por los imaginarios es posible reconocer esos factores que alimentan la violencia estructural y la violencia cultural de la que 
habló Galtung (1990), así, cuando se comprende que el entramado de violencia va mucho más allá del enfrentamiento de los cuerpos que por supuesto es desastroso, es posible reconocer que las sociedades en paz son el resultado del trabajo colaborativo por resolver las tensiones que son generadas al interior de las comunidades por diferencias entre las personas, posturas frente al uso y cuidado del medio ambiente y las cosmovisiones, aspectos todos que pueden hacerse dominantes para legitimar o rechazar ciertas manifestaciones.

En este sentido, abordar la construcción de paz desde el enfoque territorial requiere no solo del reconocimiento de las dinámicas territoriales y del impacto diferenciado del conflicto en cada lugar, sino que debe incluir una revisión sobre las formas en las que la modernidad y el afán por alcanzar un desarrollo meramente económico ha fragmentado aspectos propios de la identidad territorial, lo que genera desarraigo hacia sus culturas locales y eso se refleja en los comportamientos descuidados con los cuales se asume el cuidado del territorio para las futuras generaciones.

En este sentido, lo que sucede en el corregimiento El Llanito puede ser un ejemplo de lo que viven muchos otros lugares en el país y se abre como una realidad urgente que se debe abordar para mitigar en futuros próximos la agudización del conflicto. A partir de los imaginarios encontrados se reconoce que las nuevas generaciones adolecen de identidad y sentido de pertenencia por el territorio, a pesar de los esfuerzos de diferentes actores por fomentar el cuidado del medio ambiente estos solo se han quedado en el discurso que las personas recitan como el deber ser, pero se reconocen a sí mismos como causantes de la degradación ambiental, dado que en sus prácticas aun son descuidados con el manejo de los residuos sólidos, por ejemplo. Por otra parte, sus tradiciones históricas como la pesca artesanal quedan solo en la memoria de las personas adultas, pues en las nuevas generaciones sus conocimientos sobre esta práctica ancestral son primarios y carecen de una verdadera apropiación.

En parte el conflicto se ha dado porque se han fragmentado a las sociedades, el tejido social se ha impactado de forma severa y con ello se ha buscado minar el trabajo colaborativo, eso explica, por qué a pesar de todos los esfuerzos que se han adelantado por frenar el trasmallo, estos han sido insuficientes, pues si bien hay necesidades en familias del corregimiento para sobrevivir y adquirir su sustento diario, también se ha convertido esta técnica en una práctica facilista que evita esfuerzos de preservación ambiental y es una salida de dinero fácil.

Cuando un pueblo no siente su historia, cuando los liderazgos han sido opacados por la violencia y cuando sus habitantes más jóvenes están enfocados en salir hacia las grandes ciudades, las prácticas y los comportamientos que estos tengan, serán descuidados, no hay forma de 
resistir a los proyectos económicos de actores externos a la comunidad, porque por encima del bienestar ambiental, se ha priorizado el económico, lo cual, a largo plazo, dejará sin sostenibilidad el recurso ambiental para las futuras generaciones. En este sentido, la paz territorial no se puede entender solo como una condición de desarrollo, es necesario cuestionar el enfoque y asumir posturas críticas que empoderen a las nuevas generaciones sobre la riqueza que tienen los lugares que habitan, los territorios no son solo un dibujo en el mapa, los territorios constituyen una historia que tiene que preservarse en la memoria viva de los pueblos, si no se adquiere un compromiso por trasmitir ese legado, los territorios quedarán a merced de actores a quienes solo les interesa su explotación a costa del tejido social y del deterioro de los recursos naturales.

Los imaginarios sociales, estrechamente relacionados con las historias y hechos que ocurren en las comunidades, permitirán construir esquemas determinados del entorno, al igual que entender, argumentar e interactuar sobre una realidad concreta para la toma de decisiones sobre el tipo de desarrollo que quieren promover. En ese sentido, es indispensable vincular aquello que la población infantil y juvenil quiere ser, es decir la carrera profesional que anhelan tener y a partir de ahí, pensar cómo pueden aportar a su territorio de manera directa, esto al entender que los procesos de formación son un eje fundamental que dota a los futuros adultos de capacidades, y así aportan de forma significativa en el rescate de su memoria histórica como pueblo pescador, manteniendo vivo el legado de líderes ambientales como Lucho Arango.

Por lo tanto, según Flores (2007) citando a Albagli (2004) existe la posibilidad de establecer formas de fortalecimiento territorial creando una "interacción entre las culturas externas y locales, con resultados que se diferencian entre los territorios"; también es importante mantener los lazos de identidad desde una base de intereses comunes que busquen "proteger, valorizar y capitalizar lo que un determinado territorio tiene, sus especificidades culturales, tipicidades, naturaleza en cuanto a recursos y en cuanto a patrimonio ambiental, prácticas productivas y potencialidades económicas", permitiendo establecer unos cimientos en el sentimiento de pertenencia y actuar dentro del espacio geográfico, donde las relaciones y la localidad, están interconectadas fortaleciendo el territorio y la identidad colectiva.

Finalmente, un camino que se propone tras estas reflexiones es recurrir a la comunicación para el cambio social y sus formas de hacer acompañamiento en las comunidades para empoderar nuevos liderazgos que repercutan en el bienestar colectivo y ambiental de los territorios. Se deja por sentado que a pesar de los avances que lo logren con lo anterior, se requiere de esfuerzos intersectoriales para que los sectores privados y los organismos del estado, efectúen sus propias acciones en pro de reparar los daños cometidos a través 
de la historia contra la ciénaga y la identidad del pueblo llanitero. En cuanto a la recuperación de la cultura y sentido de pertenencia por El Llanito, la implementación de una estrategia educomunicativa, la cual constituye una segunda fase en este proyecto de investigación, se trazará consolidar relaciones de confianza y participación significativa de la comunidad a través de la conformación de un colectivo de comunicación donde se puedan conectar las experiencias individuales a las metas de la comunidad, estimulando una buena comunicación y la construcción de sujetos sociales capaces de compartir y concientizar en temas como el cuidado al medio ambiente, la protección de la ciénaga y la dignificación de la pesca artesanal, pues El Llanito es un corregimiento con gran potencial, con un largo camino hacia el turismo y el progreso.

\section{Referencias Bibliográficas}

Alonso, L. (1995). Sujeto y discurso: el lugar de la entrevista abierta en las prácticas de la sociología cualitativa. En Delgado, J. y Gutiérrez, J. (Ed.), Métodos y técnicas cualitativas de investigación en ciencias sociales. (pp. 226-255). España: Editorial Síntesis S.A.

Castañeda. S; Monroy. V; Peñuela. J; Pérez, Calderón. P; Arenas. C; y Jiménez. H. (2016). Integración económica solidaria en territorio. Aportes a la construcción de modelos y metodologías. Colombia: Unidad Administrativa Especial de Organizaciones Solidarias y Universidad Cooperativa de Colombia.

Castoriadis, C. (1997). El avance para la insignificancia. Buenos Aires: Eudeba.

Centro de Memoria Histórica. (2014). Lucho Arango: el defensor de la pesca artesanal. Colombia, Bogotá: Centro de Memoria Histórica.

D’Agostino, Agustina M. E. (2014). Imaginarios sociales, algunas reflexiones para su indagación. Anuario de Investigaciones, XXI,127-134. Disponible en: https://www.redalyc.org/pdf/3691/369139994011.pdf

Fernández, A.M. (1997). Instituciones estalladas. Buenos Aires: Eudeba.

Flores, M. (2007). La identidad cultural de territorio como base de una estrategia de desarrollo sostenible. Revista Opera, vol. 7 (7), 35-54. Recuperado de https://revistas.uexternado.edu.co/index.php/opera/article/view/1183

Gaitán, J., y Piñuel, J. (1998). Técnicas de investigación en comunicación social: Elaboración y registro de datos. España: Editorial Síntesis S.A.

Galtung, J. (2016). Capítulo quinto. La violencia: cultural, estructural y directa. Cuadernos de Estrategia. N. 186.

Jiménez-Segura, L; Gulfo, A; Hernadez-Serna, A; Álvarez, F; Márquez, V; Moreno, C; Palacio, J; Echeverry, A; Granado-Lorencio, L; Carvajal-Quintero, J. (2012). Uso tradicional de los recursos naturales pesqueros y conservación de la 
biodiversidad en regiones tropicales en desarrollo: Hacía un modelo ecológico de reconciliación. Informe final. Bogotá, Colombia: Universidad de Antioquia, Universidad de Sevilla, Agencia Española de Cooperación Internacional para el Desarrollo y Cormagdalena.

López, B. (2020, 8 de mayo). Pescando historias. Memorias de un llanitero. http://historias.plataformaupb.com/pescandohistorias/index.html

Pedroso, W. Menéndez, Y. (2017). Vinculación de adolescentes con la gestión ambiental en comunidades costeras de Cuba, a través de la educomunicación y el audiovisual participativo. Revista de comunicación. 16 (1). 147-165.

Ñaupas, H; Mejía, E; Novoa, E; Villagómez, A. (2016). Metodología de la investigación cuantitativa-cualitativa y redacción de la tesis. cuarta Edición. Bogotá: Ediciones de la U, 2014.

Pintos, J. (2004). Inclusión-exclusión. Los imaginarios sociales de un proceso de construcción social. Sémata, Ciencias Sociales y Humanidades, 16, 17-52.

Pintos, J. (2005). Comunicación, construcción de la realidad e imaginarios sociales. Utopía y praxis latinoamericana, 10(29), 37-65. Disponible en: http://www.redalyc.org/articulo.oa?id=27910293>

Randazzo, F. (2012). Los imaginarios sociales como herramienta. Revista Imagonautas. 77-96. Disponible en: DialnetLosImaginariosSocialesComoHerramienta-4781735

Revista Semana. (junio 27 de 2017). Lucho Arango, defensor de la pesca artesanal. Revista Semana. Tomado de: https://www.semana.com/contenidoseditoriales/especiales-regionales/articulo/homenaje-a-lucho-arango-lider-socialasesinado-por-los-rastrojos-en-2009/529602

Sampieri, R; Fernández, C; Baptista, P. (2014). Metodología de la investigación. Sexta edición. México: McGraw-Hill.

Sotelo, D. (2011). Hallazgos de una investigación en comunicación y desarrollo en la región Andina colombiana. Revista de Investigaciones Escuela de Ciencias Sociales, Artes y Humanidades-UNAD, 95-109. 